\title{
An Investigation of Wind-driven Topographically Controlled Motions in the Northern Adriatic
}

\author{
Milivoj Kuzmić, Mirko Orlić, Muhamed Karabeg ${ }^{a}$ and \\ Ljubomir Jeftić ${ }^{b}$ \\ Center for Marine Research Zagreb, ' Rudjer Bošković' Institute, 41000 Zagreb, \\ Croatia, Yugoslavia
}

Received 10 November 1983 and in revised form 10 August 1984

Keywords: numerical model; sea-level changes; currents; models; Adriatic Sea

\begin{abstract}
The present paper describes a three-dimensional hydrodynamical numerical model of the Northern Adriatic. The model is based on the approach of N.S. Heaps in which the integral transformations are used to reproduce the vertical distribution of velocity. The model is applied to reproduce the wind-induced motion in the Northern Adriatic during winter. Hydrographic, sea level and current data collected during the MEDALPEX are used to verify the model predictions. Analysis of the empirical data suggests that the bura wind induces the most pronounced, although transient, contribution to the Northern Adriatic current field. The model predictions clearly show the controlling influence of a shallower bottom along the Italian coast. The model to data comparison suggests for the eddy viscosity coefficient value an order of magnitude lower than expected from literature data. The quadratic law for bottom friction and wind-stress curl have been identified as possible improvements of the model.
\end{abstract}

\section{Introduction}

The influence of wind on forced motions in the Northern Adriatic is considered in this paper. There are two major aspects of this motion-namely, sea-level changes and currents. Both have been studied previously, experimentally and theoretically, and we will first briefly review these efforts.

The earliest reported studies of sea-level changes in the Northern Adriatic go back to the end of the nineteenth and beginning of the twentieth century and were limited to simple descriptive works (Mazelle, 1895, 1896; Sterneck, 1904; Kesslitz, 1911). Apparently the first researchers to relate sea-level changes to different wind-related parameters were Polli (1968) and Mosetti \& Bartole (1974). These authors were primarily concerned with the southern winds that build up water in the Northern Adriatic and occasionally flood the city of Venice.

${ }^{a}$ Present address: 3127A Evening Way, La Jolla, California 92307, U.S.A.

${ }^{b}$ Present address: Department of Planning and Environmental Protection, Committee for Building, Housing and Environmental Protection of S.R. Croatia, 41000 Zagreb, Yugoslavia. 
Mazelle (1915) was the first to discuss the influence of wind on the current field in the Northern Adriatic. Studying the relation between the surface currents and dominant winds he ascribed a case of a strong south-west current to the action of the bura wind. Recent current data analysis by Mosetti (1972) has indicated the importance of wind-generated currents in the Gulf of Trieste.

The influence of wind on sea-level changes has also been studied theoretically using hydrodynamical numerical models. Both one-dimensional (Accerboni et al., 1971; Finizio et al., 1972; Tomasin, 1973) and two-dimensional models, using either linear (Stravisi, 1972, 1973) or quadratic (Accerboni \& Manca, 1973; Michelato, 1975) laws for bottom friction, were formulated. In these models the research interest has focused on sea-level changes, but current fields (predicted as either transports or vertically averaged vectors) are not reported or commented upon. Only Stravisi (1977) reports a two-dimensional hydrodynamical model study of bura-forced circulation in the northernmost part of the Adriatic Sea.

In this paper the wind-induced motion in the Northern Adriatic during winter is studied using a three-dimensional numerical model. Hydrographic, sea-level and current data collected during the MEDiterranean ALPine EXperiment (MEDALPEX) are analysed in order to understand better the wind influence. They are also used to verify the model predictions.

\section{Model formulation}

In numerical modelling of water movements in lakes, estuaries or coastal seas vertically integrated equations of motion have often been used, particularly in tidal or storm surge models. Practical application or theoretical interest sometimes require knowledge of the vertical current profile. A number of numerical modelling efforts have been made to obtain that information but one can identify three characteristic approaches.

The first, less often taken, approach is to simulate the full set of equations of motion, numerically approximating the spatial relations in all three directions (e.g. Liggett, 1970). The second approach is to view the three-dimensional structure of a particular water body in terms of layers, integrating the equations of motion within each layer (e.g. Leendertse \& Liu, 1975). In both of these approaches rather limited vertical resolution is achieved, so when resolution is important one can take a semi-numerical approach combining numerical solution horizontally with analytical analysis in the vertical direction. Different techniques have been used to calculate the vertical profile; for example, Laplace transforms (Jelesnianski, 1970; Forristall, 1974; Nihoul, 1977), Galerkin method using B-splines (Davies, 1977), cosines (Pearce \& Cooper, 1981) or polynomials (Davies \& Owen, 1979) as basis set, and integral transform using eigenfunctions (Heaps, 1972, 1973).

In our modelling study of the hydrodynamics of the Northern Adriatic we have taken the third approach using the Heaps method in particular. Although breaking the vertical profile into eigenfunction modes does not reduce computational complexity, it does seem to offer potential for substantial insight beyond mathematical artifice. Furthermore, by starting with solving the linear problem one can better incorporate existing analytical understanding and, through gradual increase of model complexity, minimize the eventual intractability of sophisticated numerical prediction. 


\section{Basic equations}

Assuming that the water is homogeneous and incompressible, the motion hydrostatic, the coriolis parameter constant, and neglecting advective terms and lateral turbulent mixing the equations of continuity and motion (Proudman, 1953) may be written as:

$$
\begin{aligned}
& \frac{\partial \zeta}{\partial t}+\frac{\partial}{\partial x} \int_{0}^{h} u \mathrm{~d} z+\frac{\partial}{\partial y} \int_{0}^{h} v \mathrm{~d} z=0 \\
& \frac{\partial u}{\partial t}-\gamma v=-g \frac{\partial \zeta}{\partial x}+\frac{\partial}{\partial z}\left(N \frac{\partial u}{\partial z}\right) \\
& \frac{\partial v}{\partial t}+\gamma u=-g \frac{\partial \zeta}{\partial y}+\frac{\partial}{\partial z}\left(N \frac{\partial v}{\partial z}\right)
\end{aligned}
$$

where $t$ denotes time;

$\mathrm{x}, \mathrm{y}, \mathrm{z}$ are Cartesian coordinates, $x$ and $y$ measured horizontally at the undisturbed surface, $z$ is positive downwards;

$h \quad$ is the undisturbed depth of water;

$\zeta \quad$ is the elevation of the water surface;

$u, v \quad$ are the horizontal components of current at depth $z$;

$N \quad$ is the coefficient of vertical eddy viscosity;

$\gamma \quad$ is the Coriolis parameter; and

$g \quad$ is the acceleration of gravity.

In order to solve the above system of equations a specification of initial and boundary conditions is necessary. In this model the state of rest is assumed initially.

At the free surface $(z=0)$ :

$$
-\rho N \frac{\partial u}{\partial z}=F_{\mathrm{s}} \text { and }-\rho N \frac{\partial v}{\partial z}=G_{\mathrm{s}}
$$

is required where $\rho$ is the density of water, assumed to be uniform and constant; $F_{\mathrm{s}}$ and $G_{\mathrm{s}}$ are the components of wind stress at the surface in $x$ and $y$ directions, respectively.

At the sea bottom $(z=h)$ linear slip is assumed, i.e.

$$
-\rho N \frac{\partial u}{\partial z}=k \rho u_{\mathrm{h}} \text { and }-\rho N \frac{\partial v}{\partial z}=k \rho v_{\mathrm{h}}
$$

where $k$ is the coefficient of bottom friction, and $u_{\mathrm{h}}, v_{\mathrm{h}}$ are bottom values of horizontal currents.

Along the solid boundary zero normal horizontal flow is assumed, while a radiation condition is postulated at the open boundary.

\section{Eigenfunction method}

The above defined problem can be solved using the eigenfunction method. A detailed derivation and discussion of the method, also called integral and spectral, can be found in 
Heaps $(1972,1973)$. Since the method is somewhat unusual we find it appropriate to include a brief outline here.

If one defines transformed current components as:

$$
\hat{u}_{r}=\frac{1}{h} \int_{0}^{h} f_{r}(z) u \mathrm{~d} z \text { and } \hat{v}_{r}=\frac{1}{h} \int_{0}^{h} f_{r}(z) v \mathrm{~d} z,
$$

where $f_{r}(z)$ is an as yet undefined set of $r$ kernels of the transformation, one can obtain the equations of motion for the transformed components multiplying eqns (2) and (3) by $f_{r}(z)$ and integrating with respect to $z$ :

$$
\begin{aligned}
& \frac{\partial \hat{u}_{r}}{\partial t}-\gamma \hat{v}_{r}=-g a_{r} \frac{\partial \zeta}{\partial x}+\frac{1}{h} \int_{0}^{h} f_{r}(z) \frac{\partial}{\partial z}\left(N \frac{\partial u}{\partial z}\right) \mathrm{d} z \\
& \frac{\partial \hat{v}_{r}}{\partial t}+\gamma \hat{u}_{r}=-g a_{r} \frac{\partial \zeta}{\partial y}+\frac{1}{h} \int_{0}^{h} f_{r}(z) \frac{\partial}{\partial z}\left(N \frac{\partial v}{\partial z}\right) \mathrm{d} z,
\end{aligned}
$$

where $a_{r}=1 / h \int_{0}^{h} f_{r}(z) \mathrm{d} z$.

These equations can be further simplified choosing $f_{\mathrm{r}}(z)$ to be eigenfunctions of the following boundary value problem:

$$
\begin{gathered}
\frac{\mathrm{d}}{\mathrm{d} z}\left(N \frac{\mathrm{d} f_{r}}{\mathrm{~d} z}\right)=-\lambda_{r} f_{r} \\
\frac{\mathrm{d} f_{r}}{\mathrm{~d} z}=0, f_{r}=1 \text { at } z=0 \\
N_{h} \frac{\mathrm{d} f_{r}}{d z}+k f_{r}=0 \text { at } z=h,
\end{gathered}
$$

where $\lambda_{r}$ are the eigenvalues of the appropriate vertical eddy viscosity operator, and $f_{r}$ is $f_{r}(z)$ with explicit $z$-dependence omitted.

Solving this problem for the case of depth independent $N$ and linear slip bottom condition, Heaps $(1972,1973)$ obtains:

$$
\lambda_{r}=N \alpha_{r}^{2} / h^{2} \text { and } f_{r}=\cos \alpha_{r} \xi,
$$

where $\xi$ is the normalized depth, i.e. equal to $z / h$, and $\alpha_{r}$ is the $r$ th positive root of $\alpha_{r} \operatorname{tg} \alpha_{r}$ $=c(c=k h / N)$.

After carrying out necessary mathematics and applying the surface and bottom boundary conditions the equations of motion read:

$$
\begin{aligned}
& \frac{\partial \hat{u}_{r}}{\partial t}+\lambda_{r} \hat{u}_{r}-\gamma \hat{v}_{r}=-g a_{r} \frac{\partial \zeta}{\partial x}+\frac{F_{\mathrm{s}}}{\rho h} \\
& \frac{\partial \hat{v}_{r}}{\partial t}+\lambda_{r} \hat{v}_{r}+\gamma \hat{u}_{r}=-g a_{r} \frac{\partial \zeta}{\partial y}+\frac{G_{\mathrm{s}}}{\rho h} .
\end{aligned}
$$

Defining the inverse transformation as:

$$
u=\sum_{\mathrm{r}=1}^{\infty} A_{r} f_{r} \text { and } v=\sum_{\mathrm{r}=1}^{\infty} B_{r} f_{r}
$$


where, for constant $N, A_{r}=\psi_{r} \hat{u}_{r}, B_{r}=\psi_{r} \hat{v}_{r}, \psi_{r}=2 /\left(1+a_{r} \cos \alpha_{r}\right)$, and $a_{r}=\sin \alpha_{r} / \alpha_{r}$, one can substitute (15) into (1) to obtain the equation of continuity for the transformed components:

$$
\frac{\partial \zeta}{\partial t}+\sum_{r=1}^{\infty}\left[\frac{\partial}{\partial x}\left(h a_{r} \psi_{r} \hat{u}_{r}\right)+\frac{\partial}{\partial y}\left(h a_{r} \psi_{r} \hat{v}_{r}\right)\right]=0 .
$$

Heaps $(1972,1973)$ further shows that only finite expansion may be considered so that (15) reads:

where

$$
u=\sum_{r=1}^{M} \psi_{r} \hat{u}_{r} f_{r}+\Delta u \text { and } v=\sum_{r=1}^{M} \psi_{r} \hat{v}_{r} f_{r}+\Delta v
$$

and $M$ is a number of modes.

$$
\Omega=\frac{2 h}{\rho \mathrm{N} \pi^{2}}\left[\left(3 \xi^{2}-6 \xi+2\right) \frac{\pi^{2}}{12}-\sum_{r=1}^{M-1} \frac{\cos r \pi \xi}{r^{2}}\right],
$$

After reducing summation in (16) to only $M$ terms one is left with $2 M+1$ equations to be solved numerically instead of the initial three [eqns (1), (2) and (3)]. This increase in the number of equations is the price to be payed for the gain in vertical resolution.

\section{Numerical formulation}

Numerical solution of the above defined set of partial differential equations can be accomplished using different approximation techniques and choosing among many schemes reported in the literature. We have used the same forward-time, staggeredspace finite difference scheme proposed by Heaps (1972). This scheme, introduced by Sielecki (1968), achieves computational economy by using appropriate, recent computed values and assures computational stability by proper treatment of the Coriolis term. The sequence of evaluation together with general notation for the grid is indicated in Figure 1. This particular discretization then yields $1+2 M$ difference equations, namely:

$$
\begin{gathered}
\delta_{t}(\zeta)_{t}=-\sum_{r=1}^{M} a_{r} \psi_{r}\left[\delta_{x}\left(h^{u} \hat{u}_{r}\right)_{i}+\delta_{y}\left(h^{v} \hat{v}_{r}\right)_{n}\right] \\
\delta_{t}\left(\hat{u}_{r}\right)_{t}=-\lambda_{r, i}^{u} \triangle_{2}\left(\hat{u}_{r}\right)_{t}+\gamma \triangle_{4}\left(\hat{v}_{r}\right)_{n}-g a_{r} \delta_{x}(\zeta)_{i+1}+\frac{F_{\mathrm{s}, i}^{u}(t)}{\rho h_{i}^{u}} \quad r=1, M \\
\delta_{t}\left(\hat{v}_{r}\right)_{t}=-\lambda_{r, i}^{v} \triangle_{2}\left(\hat{v}_{r}\right)_{t}-\gamma \triangle_{4}\left(\hat{u}_{r}\right)_{i}-g a_{r} \delta_{y}(\zeta)_{i+n}+\frac{G_{\mathrm{s}, i}^{v}(t)}{\rho h_{i}^{v}} \quad r=1, M
\end{gathered}
$$

where the difference and averaging operators are of the form:

$$
\begin{gathered}
\delta_{t}(A)_{t}=\left[A_{i}(t+\Delta t)-A_{i}(t)\right] / \Delta t \\
\delta_{x}(A)_{i}=\left[A_{i}(t)-A_{i-1}(t)\right] / \Delta x \\
\delta_{x}(A)_{i+1}=\left[A_{i+1}(t+\Delta t)-A_{i}(t+\Delta t)\right] / \Delta x
\end{gathered}
$$




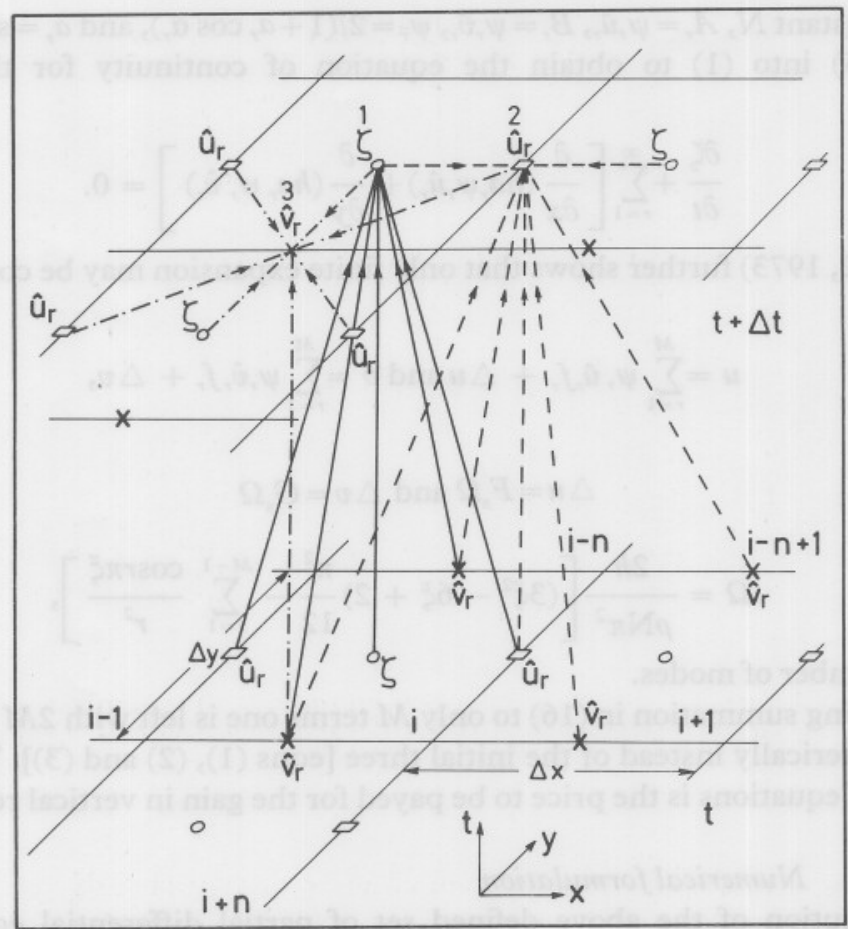

Figure 1. General notation for the finite-difference grid and sequence of evaluation. Symbols $\bigcirc, \square$ and $\times$ indicate places in the computational box where the elevation, $u$-component and $v$-component of velocity are calculated respectively.

$$
\begin{gathered}
\delta_{y}(A)_{n}=\left[A_{i-n}(t)-A_{i}(t)\right] / \Delta y \\
\delta_{y}(A)_{i+n}=\left[A_{i}(t+\Delta t)-A_{i+n}(t+\Delta t)\right] / \Delta y \\
\triangle_{2}(A)_{t}=\left[A_{i}(t+\Delta t)+A_{i}(t)\right] / 2 \\
\triangle_{4}(A)_{i}=\left[A_{i-1}(t+\Delta t)+A_{i}(t+\Delta t)+A_{i+n-1}(t+\Delta t)+A_{i+n}(t+\Delta t)\right] / 4 \\
\triangle_{4}(A)_{n}=\left[A_{i-n}(t)+A_{i-n+1}(t)+A_{i}(t)+A_{i+1}(t)\right] / 4
\end{gathered}
$$

The scheme has been successfully used before in numerical modelling studies (e.g. Henry \& Heaps, 1976). The stability problem has been avoided applying the Courant-Friedrichs-Lewy criterion in the form:

$$
\Delta t \leqslant \frac{\Delta x \Delta y}{\sqrt{g h_{\max }\left(\Delta x^{2}+\Delta y^{2}\right)}}
$$




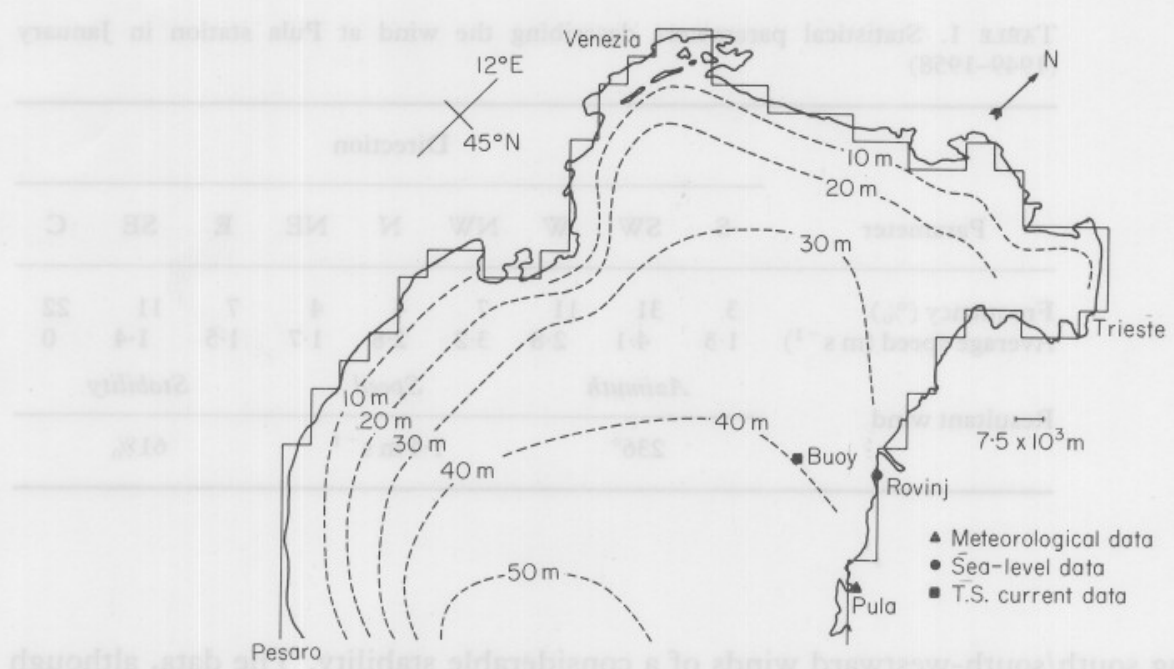

Figure 2. Geometry and bottom topography of the Northern Adriatic, with model boundaries and map of MEDALPEX stations considered in the analysis.

Nevertheless, one should bear in mind that the original CFL criterion has been derived for a simple wave equation and that the alternative to formal analysis of more complicated equations of contemporary interest is its conservative use and numerical experimentation.

\section{Application to the Northern Adriatic}

The Northern Adriatic as defined in this paper is the north-west part of the Adriatic Sea bounded on the south by the line connecting the cities of Pula on the Yugoslav and Pesaro on the Italian coasts. The area considered in the model is shown in Figure 2. As can be seen from Figure 2, part of the basin along the Italian coast is more shallow with slowly changing topography whereas the eastern part along the Yugoslav coast is steeper and deeper.

Under the winter conditions, considered for modelling in this study, the water column is well mixed and homogeneous (Franco et al., 1982), which warrants the use of a barotropic model.

Since the wind stress applied at the sea surface is the only mechanism of forcing, the winter wind field above the area has been analysed in greater detail. We have at our disposal the statistics on wind direction and magnitude as well as the resultant winds for Pula station, for the month of January over a ten-year period (1949-1958). These data are summarized in Table 1 as published in Penzar (1977) except that the wind direction data have been changed to reflect the oceanographic convention. This convention has been used throughout the paper for both the winds and currents. As can be seen from Table 1 the south-westward wind dominates in winter regarding both frequency and average speed. This wind most often has the character of a bura and develops between the quasi-stationary Eurasian anticyclone and cyclonic disturbances over the Mediterranean and the Adriatic. The resultant winds also reflect the presence of the bura 
TABLe 1. Statistical parameters describing the wind at Pula station in January (1949-1958)

\begin{tabular}{|c|c|c|c|c|c|c|c|c|c|}
\hline \multirow[b]{2}{*}{ Parameter } & \multicolumn{9}{|c|}{ Direction } \\
\hline & S & SW & w & NW & $\mathrm{N}$ & NE & $\mathrm{E}$ & SE & C \\
\hline $\begin{array}{l}\text { Frequency }(\%) \\
\text { Average speed }\left(\mathrm{m} \mathrm{s}^{-1}\right)\end{array}$ & $\begin{array}{l}3 \\
1 \cdot 3\end{array}$ & $\begin{array}{l}31 \\
4 \cdot 1\end{array}$ & $\begin{array}{l}11 \\
2 \cdot 8\end{array}$ & $\begin{array}{l}7 \\
3 \cdot 2\end{array}$ & $\begin{array}{l}4 \\
2 \cdot 8\end{array}$ & $\begin{array}{l}4 \\
1 \cdot 7\end{array}$ & $\begin{array}{l}7 \\
1 \cdot 5\end{array}$ & $\begin{array}{l}11 \\
1 \cdot 4\end{array}$ & $\begin{array}{r}22 \\
0\end{array}$ \\
\hline \multirow{2}{*}{ Resultant wind } & \multicolumn{3}{|c|}{ Azimuth } & \multicolumn{3}{|c|}{ Speed } & \multicolumn{3}{|c|}{ Stability } \\
\hline & \multicolumn{3}{|c|}{$236^{\circ}$} & \multicolumn{3}{|c|}{$1.4 \mathrm{~m} \mathrm{~s}^{-1}$} & \multicolumn{3}{|c|}{$61 \%$} \\
\hline
\end{tabular}

indicating south/south-westward winds of a considerable stability. The data, although limited to just one station on the Yugoslav coast, clearly indicate the importance of the bura and justify analysis of its influence on water motions in the Northern Adriatic.

\section{Numerical values of different parameters}

Boundaries of the North Adriatic are schematized to fit a field of $31 \times 24$ rectangular boxes of $7.5 \mathrm{~km}$ in both the $x$ (north-eastward) and $y$ (north-westward) directions. Conservative use of CFL criterion for this grid size and maximum depth of $60 \mathrm{~m}$ yields the time increment of $2 \mathrm{~min}$. For the parameters $\gamma, \rho$ and $g$ the values of $1.03 \times 10^{-4} \mathrm{~s}^{-1}$, $1025 \mathrm{~kg} \mathrm{~m}^{-3}$ and $9.81 \mathrm{~m} \mathrm{~s}^{-2}$ were used, respectively.

The wind stress at the sea surface is usually defined as:

$$
F_{\mathrm{s}}=C_{\mathrm{D}} \rho_{\mathrm{a}} W_{x} \sqrt{W_{x}^{2}+W_{y}^{2}} \text { and } G_{\mathrm{s}}=C_{\mathrm{D}} \rho_{\mathrm{a}} W_{y} \sqrt{W_{x}^{2}+W_{y}^{2}},
$$

where $C_{\mathrm{D}}$ is non-dimensional drag coefficient, $\rho_{\mathrm{a}}$ is air density and $W_{x}$ and $W_{y}$ are $x$ and $y$ components of the wind speed measured at $10 \mathrm{~m}$ above water. Different values have been suggested for the drag coefficient. Following reasoning of Simons(1980) we have chosen $C_{\mathrm{D}}=2.5 \times 10^{-3}$ which together with $\rho_{\mathrm{a}}=1.247 \mathrm{~kg} \mathrm{~m}^{-3}$ and a south-westward wind of $5 \mathrm{~m} \mathrm{~s}^{-1}$ gives $F_{\mathrm{s}}=-0.078 \mathrm{Nm}^{-2}$ and $G_{\mathrm{s}}=0$.

We have assumed that constant $N$ down the water column is an acceptable approximation for winter conditions and allowed its horizontal variation to be governed by the relation $N / h=$ const. which is a consequence of keeping the same set of eigenfunctions and having the bottom friction coefficient constant over the modelled area. For the value of $N=10^{-2} \mathrm{~m}^{2} \mathrm{~s}^{-1}$, as suggested in a previous study of winter residual dynamics of the area (Hendershott \& Rizzoli, 1976), and assuming an average depth of $40 \mathrm{~m}$, the $N$ to $h$ ratio becomes equal to $2.5 \times 10^{-4} \mathrm{~m} \mathrm{~s}^{-1}$.

A linear slip bottom condition has already been assumed [eqn (5)]. We have used the value of $2.5 \times 10^{-3} \mathrm{~m} \mathrm{~s}^{-1}$ for the coefficient of bottom friction $(k)$ as proposed by Kaese \& Tomczak (1974) in their study of residual and wind-driven winter circulation of the Adriatic Sea. This choice of $k$ and $N / h$ keeps the parameter $c=\mathrm{kh} / \mathrm{N}$ equal to 10 . 
In order to allow radiation of wave energy through the open boundary the normal, in our case $v$-component, of transport is requested to be in phase with the elevation at the boundary which may be written as:

$$
\bar{v} h=A \zeta,
$$

where $\bar{v}=\frac{1}{h} \int_{0}^{h} v \mathrm{~d} z$, and $A$ is the admittance equal to $-\sqrt{g h}$. For the transformed components this condition, in simplified form, reduces to:

$$
\psi_{1} a_{1} \hat{v}_{1}=A \zeta / h
$$

The admittances $A$ have been calculated using the depth at appropriate points.

\section{Basic numerical experiments}

Two basic experiments have been designed in order to understand better the influence of bottom topography; one with a flat bottom of an average $40 \mathrm{~m}$ depth and the other using the real topography. In both cases the previously described wind has been suddenly applied and maintained uniform and constant throughout the simulation.

Since the only forcing function has been constant in time, some quasi-steady condition should be expected. A number of runs have been made for up to 72 simulated hours but it was found that a reasonably steady situation is attained after only $48 \mathrm{~h}$. This period of time is then taken to characterize the model transient behaviour. The four major output fields, namely the sea-level change, vertically averaged current, surface current and bottom current, were then plotted and analysed.

The sea-level changes for the flat bottom case are plotted in Figure 3(a). The steady surface has a regular windward slope. Besides being regular the elevation change is also rather small. Lateral deflection due to the Coriolis force is visible. The vertically averaged currents in this case are also small, as Figure 3(b) reveals. This is only to be expected bearing in mind that these currents are caused by the vorticity of the wind stress, irregularity of the bottom topography or open boundary condition. So, flat bottom, uniform wind stress and 'neutral' boundary condition in a given geometry can produce only marginal effects. A simple surface velocity field, consisting of the wind drift and gradient current contributions properly deflected to the right, is given in Figure 3(c). Figure 3(d) illustrates the weaker, bottom, compensating current field.

The change introduced by the real topography is clearly visible in Figure 4 . The elevation changes are more pronounced and less regular as seen in Figure 4(a). Due to the variable depth, the wind stress component parallel to the local depth contour produced so called bottom-slope current, as revealed in Figure 4(b). This result conforms with the theoretical results of Weenink (1958) and Weenink \& Groen (1958). Stronger currents along the shallower Italian coastal zone are also visible in the surface [Figure 4(c)] and bottom [Figure 4(d)] fields. These results constitute the basis for numerical experiments inspired and limited by available experimental data. 

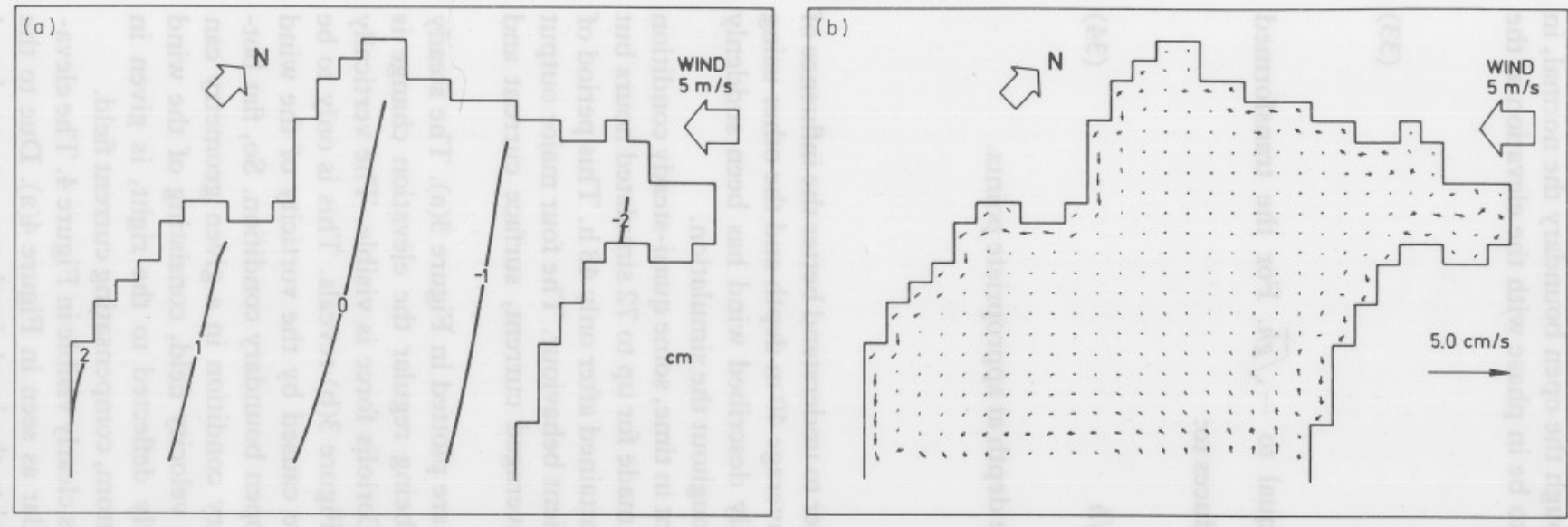

Figure 3 (a) Sea-level distribution predicted by the model for the flat bottom. (b) Vertically averaged currents predicted by the model for the flat bottom. (c) Surface currents $(z=0)$ predicted by the model for the flat bottom. (d) Bottom currents $(z=h)$ predicted by the model for the flat bottom. 

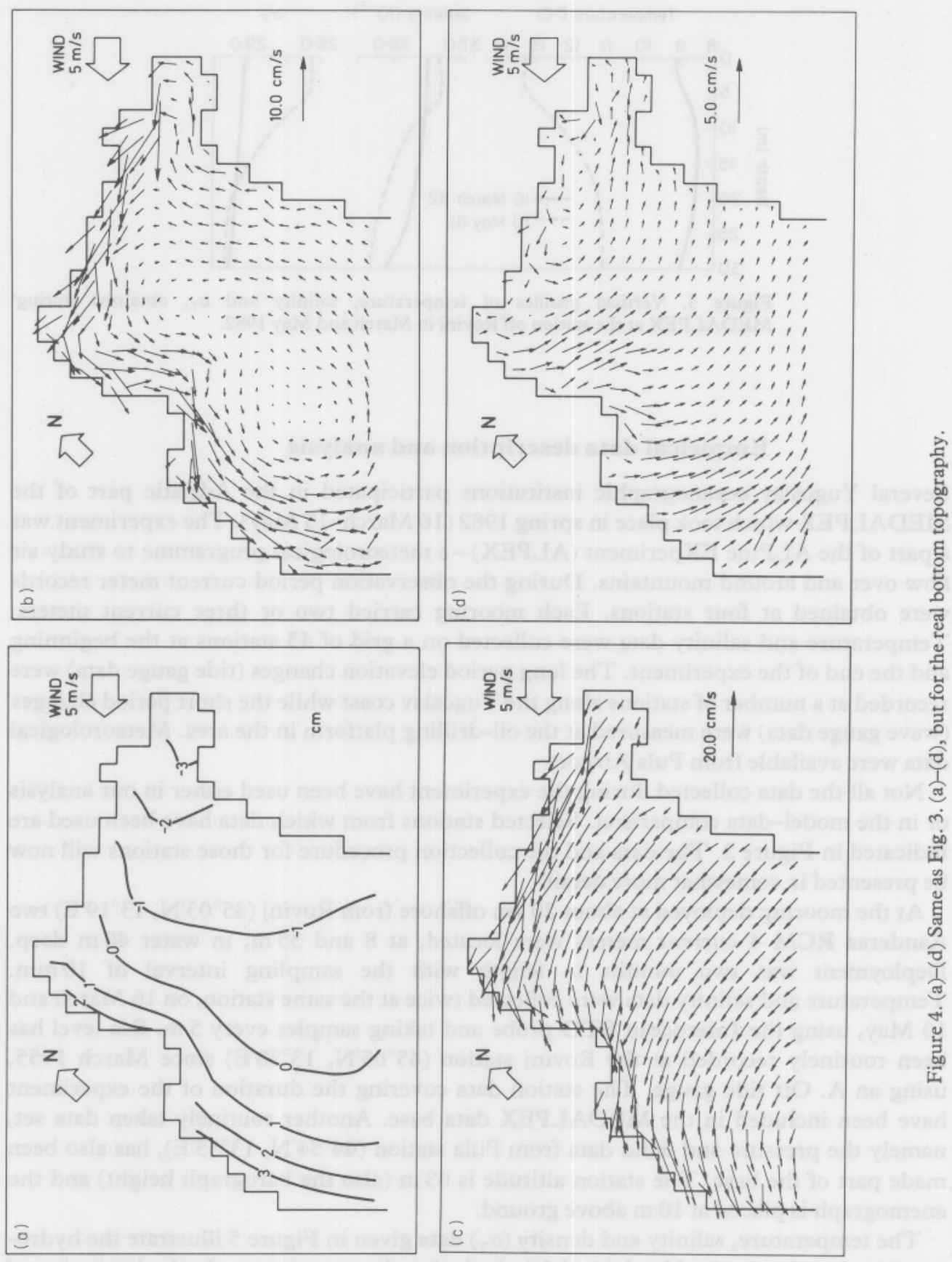


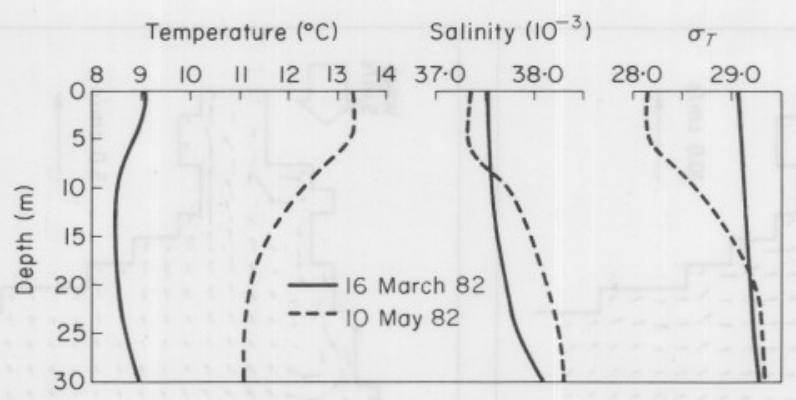

Figure 5. Vertical profiles of temperature, salinity and $\sigma_{T}$, obtained during MEDALPEX at the station off Rovinj in March and May 1982.

\section{Empirical data description and analysis}

Several Yugoslav oceanographic institutions participated in the Adriatic part of the MEDALPEX which took place in spring 1982 (16 March-15 May). The experiment was a part of the ALPine EXperiment (ALPEX) - a meteorological programme to study air flow over and around mountains. During the observation period current meter records were obtained at four stations. Each mooring carried two or three current meters. Temperature and salinity data were collected on a grid of 43 stations at the beginning and the end of the experiment. The long period elevation changes (tide gauge data) were recorded at a number of stations along the Yugoslav coast while the short period changes (wave gauge data) were measured at the oil-drilling platform in the area. Meteorological data were available from Pula Airport.

Not all the data collected during the experiment have been used either in our analysis or in the model-data comparison. Selected stations from which data have been used are indicated in Figure 2. The data and the collection procedure for those stations will now be presented ir. somewhat more detail.

At the mooring deployed at about $20 \mathrm{~km}$ offshore from Rovinj $\left(45^{\circ} 03^{\prime} \mathrm{N}, 13^{\circ} 19^{\prime} \mathrm{E}\right)$ two Aanderaa RCM 4 current meters were located, at 8 and $35 \mathrm{~m}$, in water $40 \mathrm{~m}$ deep. Deployment was two months in length with the sampling interval of $10 \mathrm{~min}$. Temperature and salinity data were collected twice at the same station, on 16 March and 10 May, using the Interocean STD probe and taking samples every $5 \mathrm{~m}$. Sea level has been routinely recorded at the Rovinj station $\left(45^{\circ} 05^{\prime} \mathrm{N}, 13^{\circ} 38^{\prime} \mathrm{E}\right)$ since March 1955, using an A. Ott tide gauge. The station data covering the duration of the experiment have been included in the MEDALPEX data base. Another routinely taken data set, namely the pressure and wind data from Pula station $\left(44^{\circ} 54^{\prime} \mathrm{N}, 13^{\circ} 55^{\prime} \mathrm{E}\right)$, has also been made part of the base. The station altitude is $63 \mathrm{~m}$ (also the barograph height) and the anemograph is placed at $10 \mathrm{~m}$ above ground.

The temperature, salinity and density $\left(\sigma_{\mathrm{T}}\right)$ data given in Figure 5 illustrate the hydrographic situation in the Northern Adriatic during the experiment. At the beginning of the experiment all three variables indicated a nearly homogeneous water column. That situation is characteristic of the Northern Adriatic winter because of the cold and dry air of Eurasian origin that reaches the area causing cooling and mixing of the water. Two opposing processes influence salinity: higher evaporation works towards increasing it and riverine runoffs (mainly the Po river) towards decreasing it. However, the density 


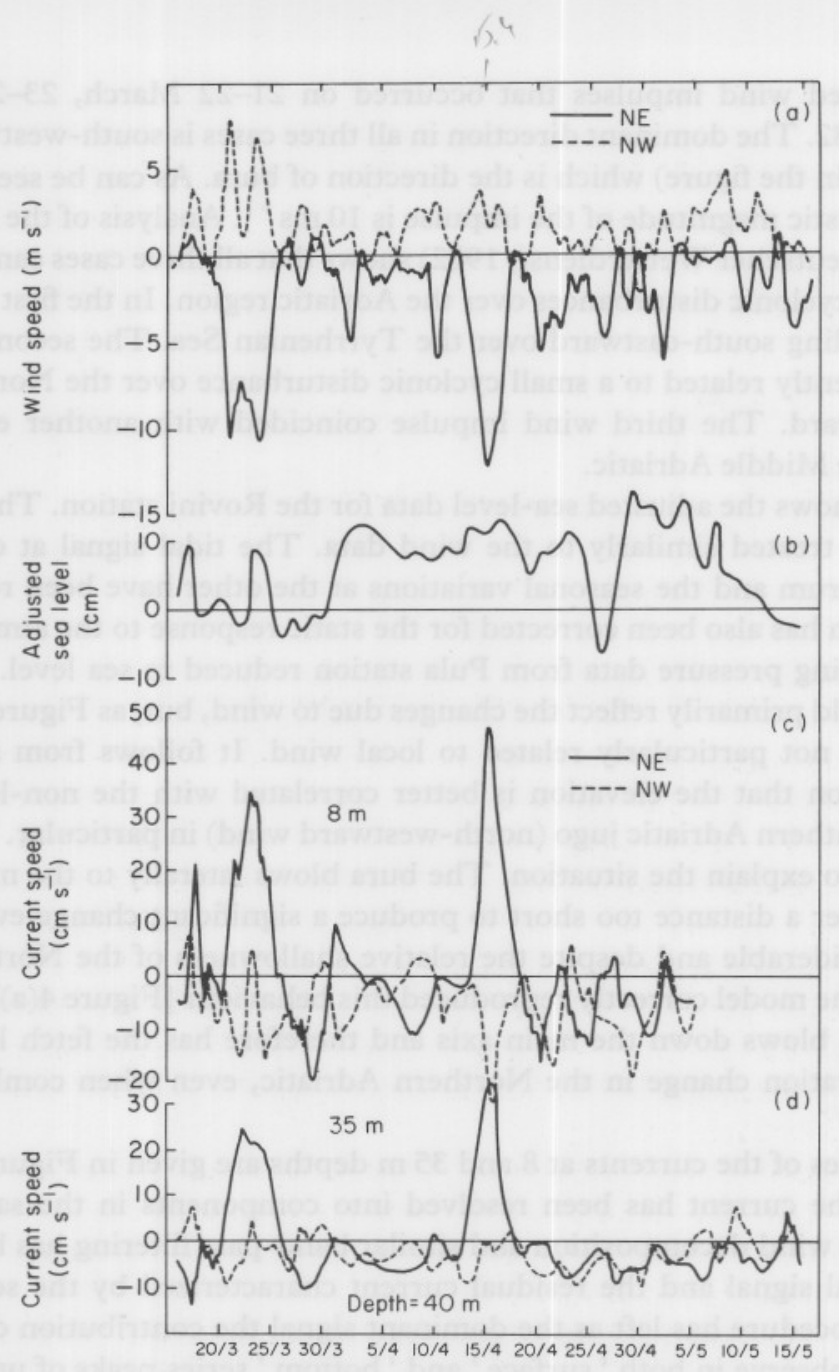

Figure 6. Band-pass filtered (cutoff frequencies $\sim 0.01-1 \mathrm{cpd}$ ) time series of (a) wind measured at the Pula station, (b) adjusted level in Rovinj, (c) 'surface' and (d) 'bottom ' currents registered at the station off Rovinj. Measurements were made in the framework of MEDALPEX, in the interval 16 March-15 May 1982.

seems to be influenced primarily by thermal homogeneity. This homogeneity is lost, however, later in spring when warming up of the surface layer begins and eventually causes formation of a thermocline. The thermocline suppresses the vertical mixing keeping the lighter freshwater in the surface layer so that the halocline and pycnocline are also formed. The data in Figure 5, taken in May, clearly reveal the latter situation.

The wind velocities, resolved into north-westward and north-eastward components with subdaily and supraseasonal periods filtered out, are given in Figure 6(a). The application of band-pass filtering has not changed the time series very much, since most of the wind energy was in the several days band. The time domain analysis of the series reveals 
three pronounced wind impulses that occurred on 21-22 March, 23-24 March and 13-15 April, 1982. The dominant direction in all three cases is south-westward (negative north-eastward in the figure) which is the direction of bura. As can be seen from Figure 6 , the characteristic magnitude of the impulse is $10 \mathrm{~ms}^{-1}$. Analysis of the related synoptic situations (Deutscher Wetterdienst, 1982) shows that all three cases can be ascribed to passages of the cyclonic disturbances over the Adriatic region. In the first case there was a cyclone travelling south-eastward over the Tyrrhenian Sea. The second incidence of bura was apparently related to a small cyclonic disturbance over the Northern Adriatic travelling eastward. The third wind impulse coincided with another eastward-going cyclone over the Middle Adriatic.

Figure 6(b) shows the adjusted sea-level data for the Rovinj station. The original time series has been treated similarly to the wind data. The tidal signal at one end of the frequency spectrum and the seasonal variations at the other have been removed. Thus filtered elevation has also been corrected for the static response to the atmospheric pressure forcing, using pressure data from Pula station reduced to sea level. The resulting time series should primarily reflect the changes due to wind, but, as Figure 6(b) suggests, the elevation is not particularly related to local wind. It follows from analysis of the synoptic situation that the elevation is better correlated with the non-local wind, the Middle and Southern Adriatic jugo (north-westward wind) in particular. The difference in fetch seems to explain the situation. The bura blows laterally to the main axis of the Adriatic, i.e. over a distance too short to produce a significant change even when wind speeds are considerable and despite the relative shallowness of the Northern Adriatic. We recall that the model correctly reproduced this behaviour [Figure 4(a)]. The jugo, on the other hand, blows down the main axis and therefore has the fetch long enough to control the elevation change in the Northern Adriatic, even when combined with the local bura.

The time series of the currents at 8 and $35 \mathrm{~m}$ depths are given in Figure $6(\mathrm{c})$ and $6(\mathrm{~d})$ respectively. The current has been resolved into components in the same coordinate system used for wind decomposition and similar band-pass filtering has been applied to remove the tidal signal and the residual current characterized by the seasonal period. The applied procedure has left as the dominant signal the contribution due to the local wind. One can observe in both 'surface ' and 'bottom' series peaks of upwind currents simultaneously with bura episodes in the wind field. The induced currents are considerable, up to $50 \mathrm{~cm} \mathrm{~s}^{-1}$. This suggests that the wind-induced current is the dominant, although transient component of the Adriatic current field. One can also observe that the response to the wind action is direct and prompt. The lack of free oscillations is evident in the data: some wave-like patterns in the current record can also be traced in the wind field. The lack of phase lag between the current and wind suggests the case of frictionally controlled flow.

Considering the model assumptions and available data it is apparent that the wind and current data are most adequate for the model verification. In order to perform the comparison, these data for the three bura cases have been averaged in a manner suggested by Scott \& Csanady (1976). The results of averaging are presented in Table 2. Again, one can see that the bura induces upwind currents at both depths. One can readily observe the small change in direction between the currents at the two levels. The magnitude difference is also somewhat unexpectedly small: the $35-\mathrm{m}$ value is only $30 \%$ smaller than the $8-\mathrm{m}$ value. One should also note that a not particularly high wind $\left(6 \mathrm{~m} \mathrm{~s}^{-1}\right)$ induces significant average currents $\left(10-20 \mathrm{~cm} \mathrm{~s}^{-1}\right)$. 
TABLE 2. Average wind and current values for the bura cases (in Cartesian and polar coordinate systems)

\begin{tabular}{cccccc}
\hline \multicolumn{2}{c}{ Wind $\left(\mathrm{m} \mathrm{s}^{-1}\right)$} & \multicolumn{2}{c}{ Currents, $8 \mathrm{~m}\left(\mathrm{~cm} \mathrm{~s}^{-1}\right)$} & \multicolumn{2}{c}{ Currents, $35 \mathrm{~m}\left(\mathrm{~cm} \mathrm{~s}^{-1}\right)$} \\
\hline$N E$ & $N W$ & $N E$ & $N W$ & $N E$ & $N W$ \\
$-5 \cdot 7$ & $2 \cdot 1$ & $18 \cdot 9$ & $-2 \cdot 7$ & $13 \cdot 2$ & $-0 \cdot 8$ \\
Speed & Azimuth & Speed & Azimuth & Speed & Azimuth \\
$6 \cdot 1$ & $246^{\circ}$ & $19 \cdot 1$ & $53^{\circ}$ & $13 \cdot 2$ & $49^{\circ}$ \\
\hline
\end{tabular}

\section{Model to data comparison}

In order to conduct a credible model to data comparison, the assumptions and limitations of the model in question should be clearly identified. In other words, one has to be sure that the data used in comparison have been taken under conditions that are in accord with the model hypotheses.

At the beginning of the experiment, as the data in Figure 5 show, the sea was nearly homogeneous with negligible thermal and haline changes through the depth. The pycnocline does develop during the experiment but all three bura episodes took place in the first half of the experiment when the sea was closer to a true barotropic state.

Next, one should consider the linearity of the model and disregard lateral of shear. Both assumptions prevent comparison of model predictions to data taken in the coastal boundary layer. In this layer non-linear effects (Weenink, 1958) and lateral shear (Robinson, 1970) become important due to decreasing depth and presence of solid boundary. Since current and STD measurements have been made about $20 \mathrm{~km}$ offshore it is reasonable to assume it was outside the coastal boundary layer.

We should also address the question of steady state. The Northern Adriatic is a relatively shallow basin with depth not exceeding $60 \mathrm{~m}$. In such a basin an average wind stress commonly develops frictionally controlled flow (Csanady, 1978) with response time shorter than diurnal period. The synoptic atmospheric disturbances on the other hand induce motions of longer duration. It is then reasonable to expect that burainduced motion will attain some sort of steady state. The lack of phase lag between the wave-like changes in the wind and current components depicted in Figure 6 further supports this notion.

Let us also comment at this point on the possible adverse effects of the open boundary condition. The vertically averaged currents plotted in Figure 4(b) reveal a cyclonic gyre formed over the modelled area. Such a kind of circulation could be a consequence of the topographic characteristics of the area, but as far as the southern part of the gyre is concerned, inadequate open boundary conditions could be suspected. In order to resolve this dilemma the model was extended to cover the whole Adriatic with the same values for all parameters except the twice coarser grid. The current data from the Adriatic model were then used as a prescribed input to the Northern Adriatic model. It turned out that the southern part of the gyre was influenced by the boundary, but the station used in model-data comparison was far enough from the boundary so as not to be affected.

The results of model to data comparison are summarized in Figure 7. In the upper part of the figure the measured vectors are given, the same as those presented in Table 2 . 


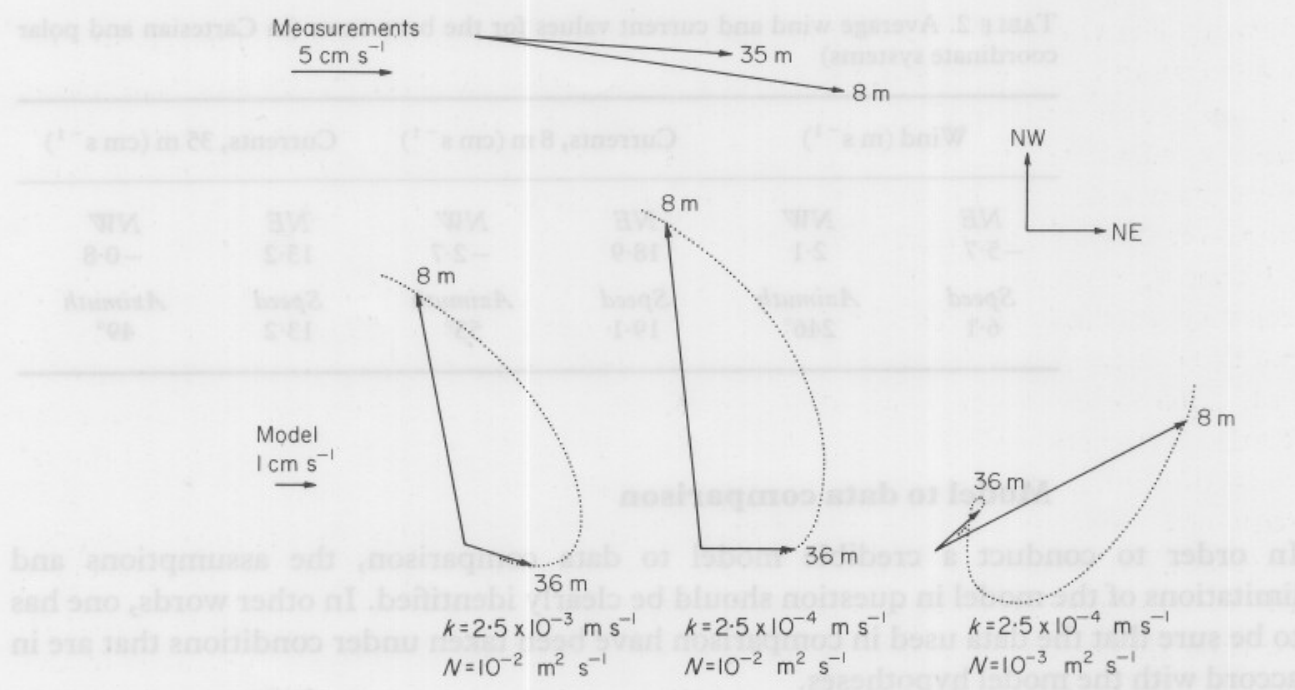

Figure 7. Model to data comparison of current vectors at two levels for different pairs of bottom friction $(k)$ and eddy viscosity $(N)$ coefficients.

The lower part of the figure shows the model results. The real topography case is, of course, presented for the wind stress corresponding to the wind speed of $7 \mathrm{~m} \mathrm{~s}^{-1}$ and three different pairs of coefficients of bottom friction $(k)$ and eddy viscosity $(N)$. The solid vectors are plotted for the depths where measured data existed and the dotted lines indicate the tips of the vectors in between. One should recall that the model allows quasicontinuous prediction of the vertical profile: quasi in the sense that no literally continuous representation is possible on a digital computer and that no more than $11 \mathrm{cal}-$ culated points was deemed necessary to represent this continuity. The lower left-most plot is the model prediction for a basic case previously presented. It is apparent that the first choice of $k$ and $N$ gives current vectors poorly related to the measured ones both in terms of magnitude and direction. The prediction in the middle indicates that an order of magnitude lowering of the values of $k$ (Kaese \& Tomczak, 1974) did not produce considerable change. It was necessary to change both $k$ and $N$ by an order of magnitude to produce significant change and refine the prediction. As the right-most plot reveals, this change rectified both vectors towards the proper direction with veering similar to that seen in the data. Checking the RMS error confirms this improvement. Its value for the original case is $12.5 \mathrm{~cm} \mathrm{~s}^{-1}$, for the intermediate case it is $12.6 \mathrm{~cm} \mathrm{~s}^{-1}$, whereas in the final case it goes down to $9 \cdot 3 \mathrm{cms}^{-1}$.

However, even in the final case some discrepancies persisted and can be summarized as follows:

(a) the magnitude of both 'surface' and 'bottom ' vectors is too small;

(b) the direction of both vectors is incorrect;

(c) the 'surface' to 'bottom ' current ratio is too high.

The inadequate wind stress can most likely explain the first two problems. The wind measured at an altitude of $73 \mathrm{~m}$ (10 m above ground in Pula), and used to calculate the stress, probably differed in both magnitude and direction from the wind simultaneously 
blowing over the sea surface. As has been shown by SethuRaman \& Raynor (1980), the ratio of wind blowing over the water to the one prevailing over the ground depends on the magnitude and direction of those winds. Their results indicate that a $7 \mathrm{~m} \mathrm{~s}^{-1}$ offshore wind blows over the sea surface at $10-11 \mathrm{~m} \mathrm{~s}^{-1}$. This kind of increase in wind speed would double the wind stress in our simulations and undoubtedly improve the model results as far as magnitudes are concerned.

However, one can reasonably doubt that a stronger stress would remove the third discrepancy. A simple analysis based on balance between the wind and bottom stress reveals that the quadratic law for bottom friction would increase the magnitude of bottom current. This raises the question of appropriateness of the linear bottom friction for the Northern Adriatic. The theoretical analysis of Csanady (1976) as well as the empirical study of Winant and Beardsley (1979) show that the linear law is valid for a lowfrequency velocity signal in the presence of more energetic oscillations at higher frequencies. As follows from our analysis of MEDALPEX data, in the Northern Adriatic the energies of wind-induced motions are higher than those that characterize the tidal signal which casts doubt on the validity of the bottom friction used in the model. The second effect that could explain this discrepancy is the wind-stress curl. We have assumed uniform wind stress in the model, due to inconclusive data, although there was some evidence of the bura being weaker near Rovinj than near Trieste and Pula. Such a wind pattern could amplify recirculation at the latitude of Rovinj and, consequently, the bottom flow.

Despite the inadequacies just described the linear three-dimensional model offers correct qualitative information on the wind-induced currents in the Northern Adriatic. Its important advantage is simplicity in identification and isolation of relevant physical processes. Once isolated these mechanisms can be studied using existing analytical knowledge. The improved understanding can then be used to build more complex models with more insight and confidence.

\section{Conclusions}

Empirical studies presented in this paper show that the wind-induced motion has significant influence on the dynamics of the Northern Adriatic. The data clearly indicate the importance of local wind forcing for the current field. More specifically, the bura wind can be singled out as the driving force that induces the most pronounced although transient contribution to the Northern Adriatic current field. For the sea-level change, however, the winds over the Middle and Southern Adriatic turn out to be more important than the bura over the Northern Adriatic.

On the theoretical side of the problem, the influence of the bura has been studied for the first time using a three-dimensional numerical model. Predicted elevation distribution resembles the one obtained by Stravisi (1977). The modifying influence of the shallower Italian coastal zone on the current field has been clearly identified in the vertically averaged current field as well as in surface and bottom fields.

The model-data comparison suggests for the eddy viscosity coefficient value an order of magnitude lower than expected from literature data. Perhaps that should be ascribed to the development of stratification in spring and consequent weakening of the vertical momentum exchange. Anyhow, the surface and bottom Ekman layers were rather thin $(\sim 10 \mathrm{~m})$. The upper current meter, apparently located at the edge of the Ekman layer, registered an upwind current for all three episodes of bura. 
The comparison also identified the weak points of the model. Resort to quadratic law for bottom friction and experimenting with a wind-stress curl seem to be the immediate steps towards improving the model. Introduction of advective terms and lateral friction would be the next problems to tackle.

On the empirical side, the relation between the coastal and open-sea winds deserves further attention. Measurements in the coastal boundary layer would facilitate validation of the non-linear model and help the understanding of the approximations of the linear model.

\section{Acknowledgements}

The authors would like to thank the Hydrometerological Office of the SR Croatia, Zagreb for supplying the meteorological data, the Institute of Oceanography and Fisheries, Split for the hydrographic data and the Hydrographic Institute of the Yugoslav Navy, Split for the sea-level data. The current data were collected in cooperation with the Center for Marine Research, Rovinj.

Two of the authors (M.O. and Mu.K.) would like to record their gratitude to Dr N. S. Heaps for discussion of certain points of his model.

This work was supported by Selfmanagement Community of Interest for Scientific Research of the SR Croatia through a grant to the Center for Marine Research Zagreb.

\section{References}

Accerboni, E. \& Manca, B. 1973 Storm surges forecasting in the Adriatic Sea by means of a twodimensional hydrodynamical numerical model. Bollettino di geofisica teorica ed applicata, 15, 3-22.

Accerboni, E., Castelli, F. \& Mosetti, F. 1971 Sull'uso di modelli matematici idrodinamici per lo studio dell'acqua alta a Venezia. Bollettino di geofisica teorica ed applicata, 13, 18-35.

Csanady, G. T. 1976 Mean circulation in shallow seas. Fournal of Geophysical Research, 81, 5389-5399.

Csanady, G. T. 1978 Water circulation and dispersal mechanisms. In Lakes-Chemistry, Geology, Physics (Lehrman, A., ed.). Springer-Verlag, New York. pp. 21-64.

Davies, A. M. 1977 The numerical solution of the three-dimensional hydrodynamic equations, using a B-spline representation of the vertical current profile. In Bottom Turbulence, Proceedings of the 8th International Liege Colloquium on Ocean Hydrodynamics (Nihoul, J. C. J., ed.). Elsevier, Amsterdam. pp. $1-25$.

Davies, A. M. \& Owen, A. 1979 Three-dimensional numerical sea model using the Galerkin method with a polynomial basis set. Applied Mathematical Modelling, 3, 421-428.

Deutscher Wetterdienst 1982 Europaisher Wetterbericht - für das fahr 1982. Offenbach am Main.

Finizio, C., Palmieri, S. \& Riccucci, A. 1972 A numerical model of the Adriatic for the prediction of high tides at Venice. Quarterly fournal of the Royal Meteorological Society, 98, 86-104.

Forristall, G. Z. 1974 Three-dimensional structure of storm-generated currents. fournal of Geophysical Research, 79, 2721-2729.

Franco, P., Jeftić, Lj., Malanotte Rizzoli, P., Michelato, A. \& Orlić, M. 1982 Descriptive model of the Northern Adriatic. Oceanologica Acta, 5, 379-389.

Heaps, N. S. 1972 On the numerical solution of the three-dimensional hydrodynamical equations for tides and storm surges. Mémoires Société Royale des Sciences de Liège, $6^{\mathrm{e}}$ série, tome I, 143-180.

Heaps, N. S. 1973 Three-dimensional numerical model of the Irish Sea. Geophysical fournal of the Royal Astronomical Society, 35, 99-120.

Hendershott, M. C. \& Rizzoli, P. 1976 The winter circulation of the Adriatic Sea. Deep-Sea Research, 23, 353-370.

Henry, R. F. \& Heaps, N. S. 1976 Storm surges in Beaufort Sea. fournal of the Fisheries Research Board of Canada, 33, 2362-2376.

Jelesnianski, C. P. 1970 'Bottom stress time-history' in linearised equations of motion for storm surges. Monthly Weather Review, 98, 462-478.

Kaese, R. H. \& Tomczak, M. Jr. 1974 Case study on distribution of a polutant continuously released into the Adriatic Sea. Unpublished report, FAO Meeting on protection of living resource and fisheries from pollution in the Mediterranean. 
Kesslitz, W. 1911 Die Sturmflut am 15. und 16. November 1910 in Pola. Mitteilungen aus dem Gebiete des Seewesens, 39, 157-163.

Leendertse, J. J. \& Liu, S.-K. 1975 A three-dimensional model for estuaries and coastal seas: Volume II, Aspects of computation. RAND Corporation Report R-1764-OWRT, $123 \mathrm{pp}$.

Liggett, J. A. 1970 Cell method for computing lake circulation. fournal of the Hydraulics Division, Proceedings of the American Society of Civil Engineers, 96, 725-743.

Mazelle, E. 1895 Springfluth in Triest. Meteorologische Zeitschrift, 12, 140-144.

Mazelle, E. 1896 Einfluss der Bora auf das Meeresniveau. Meteorologische Zeitschrift, 13, 68-70.

Mazelle, E. 1915 Meeresströmungen und Winde in der Adria. Meteorologische Zeitschrift, 32, 222-227.

Michelato, A. 1975 Numerical computation of surges induced by southern winds in Adriatic Sea. Bollettino di geofisica teorica ed applicata, 18, 322-334.

Mosetti, F. 1972 Alcune ricerche sulle correnti nel golfo di Trieste. Rivista italiana di geofisica, 21, 33-38.

Mosetti, F. \& Bartole, R. 1974 Esame dell-effetto del vento sui solevamenti di livello dell'Adriatico settentrionale. Rivista italiana di geofisica, 23, 71-74.

Nihoul, J. C. J. 1977 Three-dimensional model of tides and storm surges in a shallow well-mixed continental sea. Dynamics of Atmospheres and Oceans, 2, 29-47.

Pearce, B. R. \& Cooper, C. K. 1981 Numerical circulation model for wind induced flow. Fournal of the Hydraulics Division, Proceedings of the American Society of Civil Engineers, 107, 285-302.

Penzar, B. 1977 Tlak zraka - Vjetar. Prilozi poznavanju vremena i klime SFRf, 2, 117 pp.

Polli, S. 1968 L'eccezionale acqua alta nella laguna di Venezia in relazione agli ultimi eventi idrometeorici. Accamia nazionale dei Lincei-Quaderno, 112, 63-78.

Proudman, J. 1953 Dynamical Oceanography. Methuen, London.

Robinson, A. R. 1970 Boundary layers in ocean circulation models. Annual Review of Fluid Mechanics, 2, 293-312.

Scott, J. T. \& Csanady, G. T. 1976 Nearshore currents off Long Island. fournal of Geophysical Research, 81, 5401-5409.

SethuRaman, S. \& Raynor, G. S. 1980 Comparison of mean wind speeds and turbulence at a coastal site and an offshore location. Fournal of Applied Meteorology, 19, 15-21.

Sielecki, A. 1968 An energy-conserving difference scheme for the storm surge equations. Monthly Weather Review, 96, 150-156.

Simons, T. J. 1980 Circulation models of lakes and inland seas. Canadian Bulletins of Fisheries and Aquatic Sciences, 203, 146 pp.

Sterneck, R. 1904 Kontrolle des Nivellements durch die Flutmesserangaben und die Schwankungen des Meeresspiegels der Adria. Mitteilungen des K.u.K. Militärgeographischen Institutes, 24, 75-141.

Stravisi, F. 1972 A numerical experiment on wind effects in the Adriatic Sea. Accademia nazionale dei Lincei-Rendiconti, VIII/52, 187-196.

Stravisi, F. 1973 Analysis of a storm surge in the Adriatic Sea by means of a two-dimensional linear model. Accademia nazionale dei Lincei-Rendiconti, VIII/54, 243-260.

Stravisi, F. 1977 Bora driven circulation in Northern Adriatic. Bollettino di gefisica teorica ed applicata, 19, 95-102.

Tomasin, A. 1973 A computer simulation of the Adriatic Sea for the study of its dynamics and for the forecasting of floods in the town of Venice. Computer Physics Communications, 5, 51-55.

Weenink, M. P. H. $1958 \mathrm{~A}$ theory and method of calculation of wind effects on sea levels in a partly-enclosed sea, with special application to the southern coast of the North Sea. Koninklijk Nederlands Meteorologisch Institut-Mededelingen en Verhandelingen, 73, $111 \mathrm{pp}$.

Weenink, M. P. H. \& Groen, P. 1958 A semitheoretical, semi-empirical approach to the problem of finding wind effects on water levels in a shallow partly-enclosed sea. Proceedings-Koninklijke Academie van Wetenschappen, B61, 198-213.

Winant, C. D. \& Beardsley, R. C. 1979 A comparison of some shallow wind-driven currents. fournal of Physical Oceanography, 9, 218-220. 


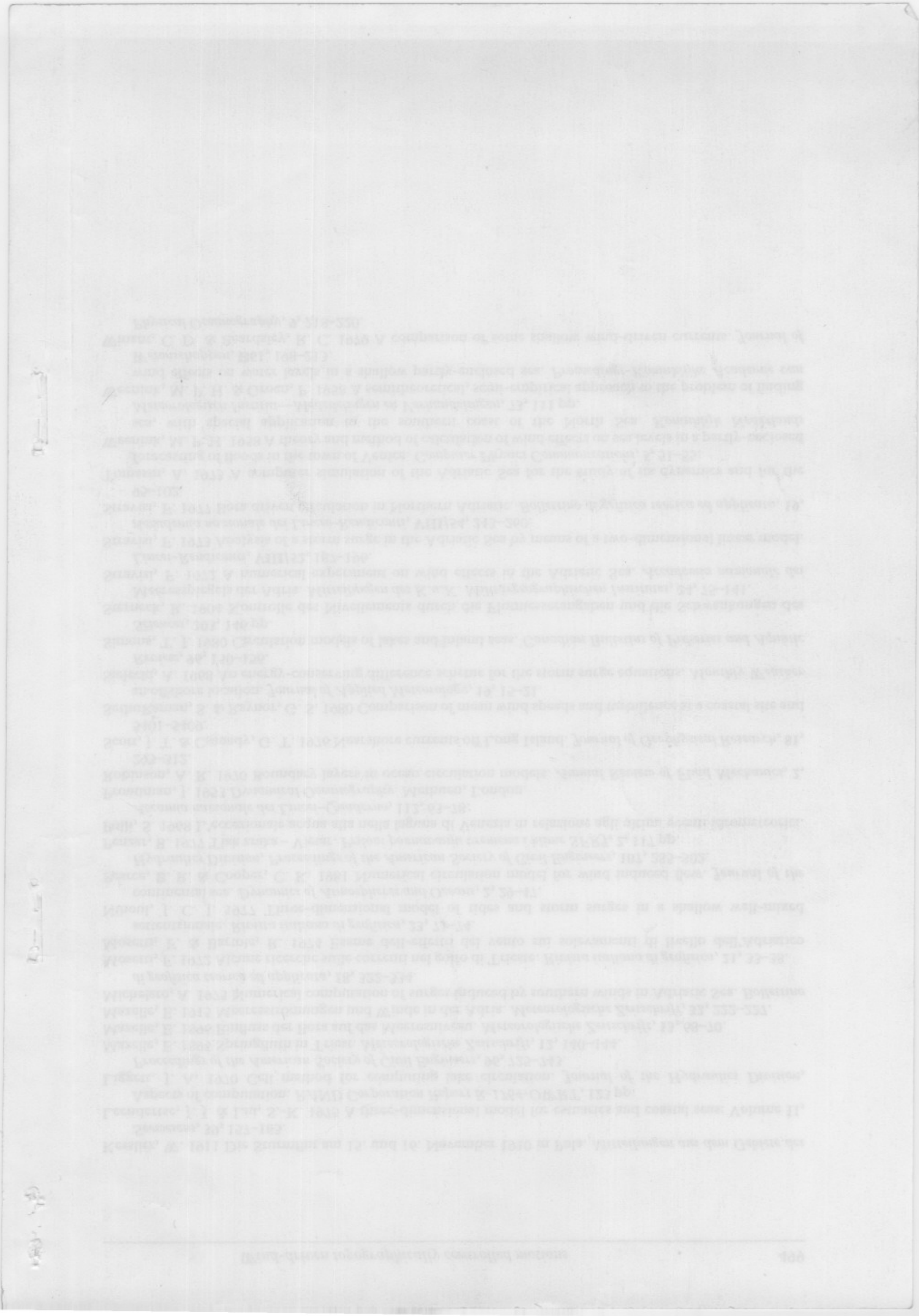

